\title{
Simple and Economic Spectrophotometric Method for Simultaneous Photosensitized Dechlorination and Decarboxylation of Isomeric Mono- and Dichlorobenzoic Acids
}

\author{
U. C. PANDE and A. H. DWIVEDI* \\ Department of Chemistry, University School of Science \\ Gujarat University, Navrangpura, Ahmedabad-380 009, Gujarat, India \\ dwivedi_ank@indiatimes.com
}

Received 17 February 2010; Accepted 10 April 2010

\begin{abstract}
Simultaneous photosensitized dechlorination and decarboxylation of isomeric mono- and dichlorobenzoic acids have been studied in the presence of naphthoxide ion in alkaline medium. The effects of the $\mathrm{pH}$, concentration of the sensitizer, concentration of the substrate, the intensity of the light and the temperature on the rate of the dechlorination have been studied. The quantum efficiency of the photodechlorination has been evaluated. The mechanisms of the photodechlorination and decarboxylation have been suggested. The method is simple, economic and effective.
\end{abstract}

Keywords: Photosensitized, Dechlorination, Decarboxylation, Chlorobenzoic acid (CBA), Dichlorobenzoic acid (DCBA), 2-Naphthol.

\section{Introduction}

Benzoic acid (BA) and its chloro derivatives are the class of compounds, which are used as preservative for glues, paints, as laboratory reagents and intermediates. They are also used in the manufacture of fungicides and dyes ${ }^{1}$. Chlorobenzoic acids are used in the study of metal ion complex formation ${ }^{2}$, metal extraction ${ }^{3}$ and hydrogen bonded adducts ${ }^{4}$. Besides controlling pests like insects, diseases etc., the pesticidal chemicals have the potentiality of affecting the life and environment adversely. Chlorobenzoic acids are hazardous and show toxicity to living beings. These compounds show toxicity mainly towards the different systems and metabolism of living beings ${ }^{5-6}$. Chlorobenzoic acid and their derivatives show hepatic changes in rats and other rodents ${ }^{7}$, toxic effects on mammalian brain $^{8}$, cytotoxicity in cultured rat hepatocytes ${ }^{9}$, and genetic degradation ${ }^{10}$. Nowadays the degradation of chlorobenzoic acids has been studied widely in the world. Different methods including the biological or microbiological degradation; which are one of the useful techniques reported in literature ${ }^{11-16}$. 


\section{S112 A. H. DWIVEDI et al.}

The photochemical reactions have been used in the detoxification of chlorobenzoic acids. The photoassisted dehalogenation and mineralization of chloro/fluorobenzoic acid derivatives in aqueous media has been done by Hidaka H. et al. ${ }^{17}$. The photocatalytic degradation of chlorobenzoic acids using semiconductor like $\mathrm{TiO}_{2}$ has been reported as one of the widely used methods for the degradation of these pollutants ${ }^{18-20}$. Solar detoxification of various pollutants including chlorobenzoic acids has been demonstrated using titania photocatalysts by Jean-Marie H. et al. ${ }^{21}$. Literature shows that the research has been done to degrade mono- and dichlorobenzoic acids using UV light, $\mathrm{O}_{3}$ and $\mathrm{O}_{3} / \mathrm{H}_{2} \mathrm{O}_{2}$ in UV light, ultrasound and Fenton's reagent ${ }^{22-24}$.

In our previous publications, we have reported the photosensitized dechlorination of isomeric mono- and dichloronitrobenzenes as well as isomeric chloroanisidine ${ }^{25-26}$. The present study reports photosensitized dechlorination of isomeric mono- and dichlorobenzoic acids in alkaline medium. The naphthoxide ion has been used as photosensitizer, which has also been used as sensitizer in alkaline medium for different compounds ${ }^{27-31}$. The photodechlorination of isomeric mono- and dichlorobenzoic acids has been studied in visible light using a $100 \mathrm{~W}$ tungsten lamp for the irradiation. The effects of different parameters e.g. $\mathrm{pH}$, concentration of the sensitizer, concentration of the substrate, the intensity of the light and the temperature on the rate of the photodechlorination, have been studied and reaction conditions have been established. The quantum efficiency of the photodechlorination has been evaluated using potassium ferrioxalate actinometer. The effect of the substrate concentration on quantum efficiency has been studied to evaluate the different excited state of the substrate molecule. The removal of chlorine from the substrate has been tested with silver nitrate. The mechanism of the photodechlorination and decarboxylation has been suggested.

\section{Experimental}

All chemicals that have been used for the experiments were of AR grade (Aldrich) and no further purification has been done. Absolute alcohol (99\%) has been used after distillation. Milli-Q water has been used for the dilution.

\section{Instrumentation}

$100 \mathrm{~W}$ tungsten filament light source (Phillips) has been used for the exposure of the sample solution. A convex lens has been used to converge the irradiation. A glass water jacket has been used to decrease the temperature of the solution. All the spectral measurements have been done on UV-Vis spectrophotometer (Spectrascan-2800-Cibacorning, England). pH of the solution has been measured using $\mathrm{pH}$ meter (Systronics, India).

\section{Procedure}

Four sets of experiment were prepared by withdrawing $2 \mathrm{~mL}$ of $1.0 \times 10^{-3} \mathrm{M}$ solution of chlorobenzoic acids in $1.0 \times 10^{-3} \mathrm{M}$ sodium hydroxide and $1 \mathrm{~mL}$ of $1.0 \times 10^{-1} \mathrm{M}$ sodium hydroxide solution in each $50 \mathrm{~mL}$ volumetric flask. $1.5 \mathrm{~mL} 1.0 \times 10^{-3} \mathrm{M}$ 2-naphthol solution was added to two flasks and solutions of all four flasks were made up to the mark with Milli-Q water. The final concentrations of chlorobenzoic acids and naphthoxide ion were $4.0 \times 10^{-5} \mathrm{M}$ and $3.0 \times 10^{-5} \mathrm{M}$ respectively. All the measurements were carried out between $\mathrm{pH}$ 11-12.

Two flasks, each containing 2-naphthol and without 2-naphthol were kept in the dark for $24 \mathrm{~h}$ while remaining similar flasks were exposed to visible light from $100 \mathrm{~W}$ tungsten lamp. The course of the reaction was followed by recording the spectrum of the exposed solution with a control solution in the range of $200-350 \mathrm{~nm}$ against reagent blank. 
The flask kept in the dark and flask exposed without sensitizer did not show any difference in the spectrum when compared to the control; while the exposed flask containing sensitizer showed decrease in the absorbance from the original spectrum, confirms that reaction takes place only in the presence of the naphthoxide ion on irradiation. Thus the reaction is photosensitized dechlorination and not normal or thermal dechlorination.

Free chloride was tested in the exposed solution with silver nitrate by observing white precipitate of $\mathrm{AgCl}$. This was compared with the control experiment run as blank without sample in which the $\mathrm{Cl}^{-}$test was found negative. The temperature of the solution was maintained at $298^{\circ} \mathrm{K}$ using water jacket. The quantum efficiency $(\phi)$ of the photodechlorination has been evaluated using potassium ferrioxalate actinometer.

\section{Molar absorptivities}

The molar absorptivities of the substrates have been calculated by measuring the absorbance of a number of known concentration solutions (Table 1). In the case of 2,3-DCBA the molar absorptivity of reaction product, which is $o$-CBA has been calculated.

\section{The reaction rate}

The decrease in the absorbance of the reaction mixture has been measured with time. The rate of the reaction has been calculated by measuring the absorbance by withdrawing $5 \mathrm{~mL}$ aliquot of the reaction solution after different time intervals at $210 \mathrm{~nm}, 233 \mathrm{~nm}$ and $211 \mathrm{~nm}$ in the case of $m$-CBA, $p$-CBA and 2,3-DCBA respectively.

A plot of $2+\log (\mathrm{OD})$ (optical density) vs. time has been plotted and was found to be a straight line with a negative slope which indicates that the reaction follows first order reaction kinetics (Figure 1). The rate constant of the reaction has been determined by using the following expression:

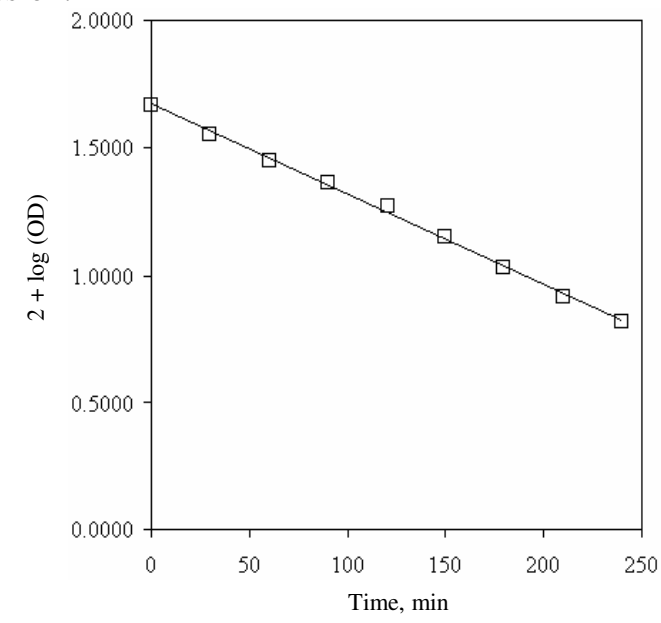

\section{Results and Discussion}

Figure 1. A typical run

Spectral characteristics

The spectra of the exposed solutions of the substrates under experimental conditions were recorded between 200-350 nm after withdrawing aliquots of the exposed solution at different time intervals. The spectrum of $m$ - and $p$-CBA showed change in the spectrum from the original compounds; while spectrum of exposed solution of $o$-CBA did not show any change (Figure 2a). 


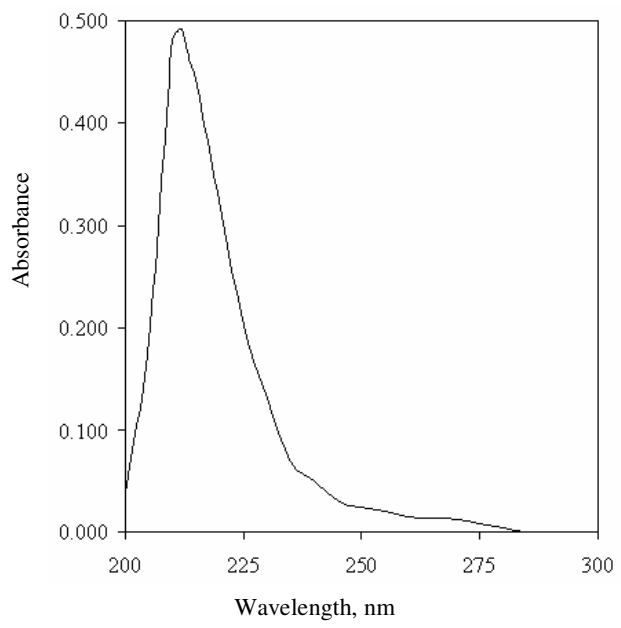

Figure 2a. Spectrum of $o$-CBA $[o-\mathrm{CBA}]=$ 5.0x10-5 M, [2-Naphthol] $=5.0 \times 10-5 \mathrm{M}$, light intensity $=11.8 \times 10^{-8} \mathrm{E} \sec ^{-1}, \mathrm{pH}=11.5$, Temperature $=298 \mathrm{~K}$

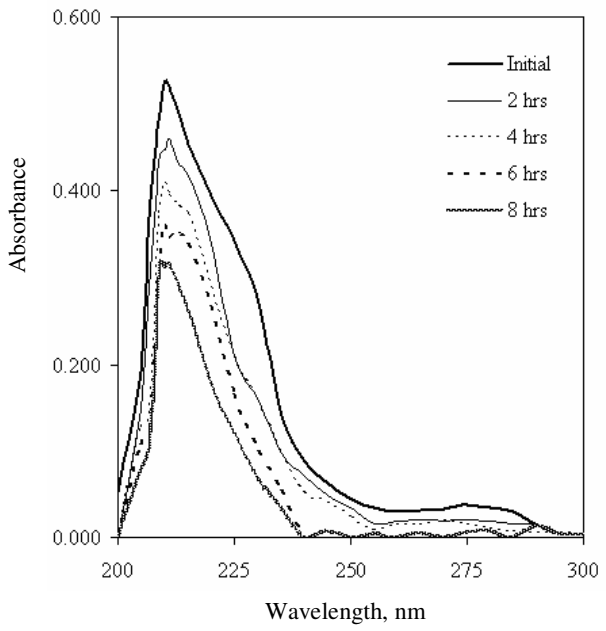

Figure 2b. Spectrum changes of $m$-CBA with time $[o-\mathrm{CBA}]=5.0 \times 10^{-5} \mathrm{M},[2-\mathrm{Naphthol}]=$ $5.0 \times 10^{-5} \mathrm{M}$, light intensity $=11.8 \times 10^{-8} \mathrm{E} \mathrm{sec}^{-1}$, $\mathrm{pH}=11.5$, Temperature $=298 \mathrm{~K}$

The spectrum of $m$-CBA and $p$-CBA, which shows $\lambda_{\max }$ at $210 \mathrm{~nm}$ and $233 \mathrm{~nm}$ does not show any shift in the $\lambda_{\max }$ but decrease in absorbance, was observed (Figure $2 b, 2 c$ ). 2,3-DCBA shows broad spectrum with $\lambda_{\max }$ at $211 \mathrm{~nm}$ with other small peak at $242 \mathrm{~nm}$. On exposure, the decrease in absorbance was measured at $211 \mathrm{~nm}$ and gradually all the peaks disappeared. The spectrum of 2,3-DCBA, which has a broad spectrum, shows the new $\lambda_{\max }$ at $212 \mathrm{~nm}$, with lower molar absorptivity (Table 1), which corresponds to the spectrum of $o$-CBA (Figure 2d), indicating the removal of only one chlorine atom from the molecule.
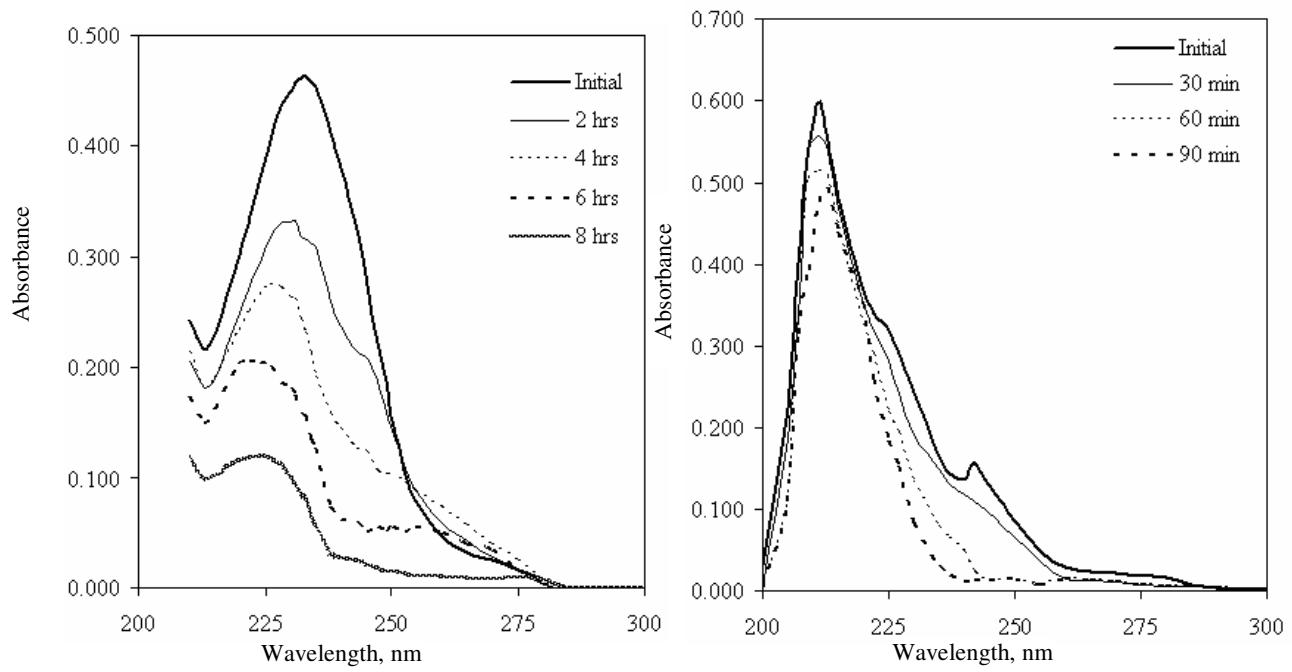

Figure 2c. Spectrum changes of $p$-CBA with time $[o-\mathrm{CBA}]=4.0 \times 10-5 \mathrm{M},[2-\mathrm{Naphthol}]=$ $5.0 \times 10^{-5} \mathrm{M}$, light intensity $=11.8 \times 10^{-8} \mathrm{E} \mathrm{sec}^{-1}$, $\mathrm{pH}=11.5$, Temperature $=298 \mathrm{~K}$
Figure 2d. Spectrum changes of 2,3-DCBA with time $2,3-\mathrm{DCBA}=4.0 \times 10^{-5} \mathrm{M}$, [2Naphthol $]=5.0 \times 10^{-5} \mathrm{M}$, light intensity= $11.8 \times 10^{-8} \mathrm{E} \mathrm{sec}^{-1}, \mathrm{pH}=11.5$, Temperature $=298 \mathrm{~K}$ 
Table 1. Experimental values of molar absorptivities $(\varepsilon)$ and effect of light intensity on rate of dechlorination and decarboxylation

\begin{tabular}{|c|c|c|}
\hline Compound & Experimental $\lambda_{\max }, \mathrm{nm}$ & Calculated $\varepsilon$ value \\
\hline $\mathrm{BA}$ & 224 & 11,975 \\
\hline$o$-CBA & 212 & 9240 \\
\hline$m-\mathrm{CBA}$ & 210 & 9845 \\
\hline$p$-CBA & 233 & 10,525 \\
\hline 2,3-DCBA & 211 & 11,675 \\
\hline Light intensity & \multicolumn{2}{|c|}{$\mathrm{k} \times 10^{3}, \min ^{-1}$} \\
\hline I $\times 10^{8}\left(\mathrm{E} \mathrm{sec}^{-1}\right)$ & $m-\mathrm{CB} A$ & $p-\mathrm{CBA}^{\mathrm{a}}$ \\
\hline 4.47 & 2.3668 & 1.8424 \\
\hline 6.72 & 4.2154 & 3.3227 \\
\hline 11.18 & 7.1823 & 5.5272 \\
\hline
\end{tabular}

$[B A]=[m-C B A]=[p-C B A]=4 \times 10^{-5} \mathrm{M},{ }^{a}[2-N a p h t h o l]=2.5 \times 10^{-5} \mathrm{M} ;{ }^{b}[2-N a p h t h o l]=2.0 \times 10^{-5}$ $M, p H=11.5$; Temperature $=298 \mathrm{~K}$

These changes in the spectrum on exposure indicate that dechlorination and decarboxylation processes occur simultaneously in the cases of $m$-CBA, $p$-CBA, while in the case of $o$-CBA no reaction takes place. The spectrum profile of monochlorobenzoic acids and of pure benzoic acid (Figure 2e) are similar under experimental conditions, confirms that the formation of major product of the photodechlorination of $\mathrm{m}$ - and $p$-CBA are similar to the product obtained by the photodegradation of benzoic acid (Figure 2e). In the case of 2,3-DCBA, the spectrum of product was similar to $o$-CBA, which confirms the formation of $o$-CBA. This indicates the removal of only single chlorine atom from the molecule takes place. Excited state of $o$-CBA molecule gets stabilized and dechlorination and decarboxylation both processes do not take place. In the case of 2,3-DCBA molecule undergoes only dechlorination and not decarboxylation. The product formed was $o$-CBA, which also does not undergo decarboxylation.

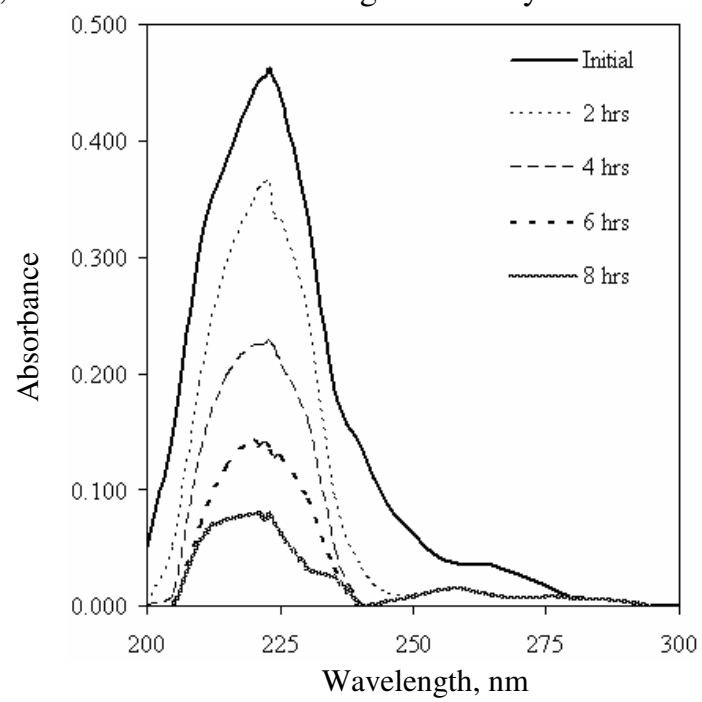

Figure 2e. Spectrum changes of benzonic acid with time $[\mathrm{BA}]=5.0 \times 10-5 \mathrm{M}$, [2-Naphthol] $=$ $5.0 \times 10^{-5} \mathrm{M}$, light intensity $=11.8 \times 10^{-8} \mathrm{E} \mathrm{sec}^{-1}, \mathrm{pH}=11.5$, Temperature $=298 \mathrm{~K}$ 


\section{The rate of the reaction}

The decrease in the absorbance at particular wavelength was measured at different time intervals; which reaches to minimum and becomes constant, indicating the completion of the reaction. The decrease in the absorbance as a function of the substrate concentration, at 210 $\mathrm{nm}, 233 \mathrm{~nm}$ and $211 \mathrm{~nm}$ has been used to calculate the rate constant for $m$-CBA, $p$-CBA and 2,3-DCBA respectively. Here the product is $o$-CBA in the case of 2,3-DCBA; which absorbs at $212 \mathrm{~nm}$ and hence the rate has been calculated by measuring the decrease in absorbance at $211 \mathrm{~nm}$ as both the wavelengths for the product and substrate are very close.

The rates of the dechlorination for $m-, p$-CBA and 2,3-DCBA have been calculated (Table 2). The photosensitized dechlorination shows different rates for different mono-and dichlorobenzoic acids in experimental conditions. The order of the dechlorination follows $p->m$ $>o$-chlorobenzoic acid. However $o$-CBA does not undergo dechlorination and decarboxylation reaction. It appears that excited state of $o$-CBA gets stabilized. The 2,3-DCBA shows that only chlorine atom of position 3 is removed, while chlorine atom of position 2 is retained. The excited molecule undergoes dechlorination but decarboxylation has not been observed. The $\lambda_{\max }$ and molar absorptivity of the product are in agreement with $o$-CBA. The rate of the reaction is faster than $m$-CBA. It appears that the excited molecule of 2,3-DCBA ejects the $m$-chlorine atom faster to achieve the lower energy level of stabilized excited $o$-CBA.

Table 2. Quantum efficiency and rate of dechlorination and decarboxylation

\begin{tabular}{cccc}
\hline S. No. & Compound & $\Phi$-Value & ${\mathrm{k} \mathrm{x} 10^{3}, \mathrm{~min}^{-1}}^{-1}$ \\
\hline 1 & $\mathrm{BA}^{\mathrm{a}}$ & 0.1311 & 7.2163 \\
2 & $o-\mathrm{CBA}$ & - & - \\
3 & $m$-CBA & 0.0434 & 2.0936 \\
4 & $p-\mathrm{CBA}^{\mathrm{a}}$ & 0.1052 & 5.5830 \\
5 & $2,3-\mathrm{DCBA}^{\mathrm{a}}$ & 0.0602 & 3.0706 \\
\hline
\end{tabular}

$[B A]=[m-C B A]=[p-C B A]=[2,3-D C B A]=4.0 \times 10^{-5} \mathrm{M},{ }^{a}[2-$ Naphthol $]=2.5 \times 10^{-5} \mathrm{M} ;$ ${ }^{b}[2-\mathrm{Naphthol}]=2.0 \times 10^{-5} \mathrm{M}$, Light intensity $=11.18 \times 10^{-8} \mathrm{E} \mathrm{sec}^{-1} ; \mathrm{pH}=11.5$; Temperature $=298 \mathrm{~K}$

\section{Effect of the variables}

\section{Effect of the $\mathrm{pH}$}

The photosensitizer effect of 2-naphthol has not been observed in the acidic and neutral medium. The rate constant of the photosensitized reaction has been calculated for $m$ - and $p$-CBA at different $\mathrm{pH}$ between $10.5-12.5$ with $0.5 \mathrm{pH}$ interval. It has been observed that as $\mathrm{pH}$ decreases the rate of the reaction decreases and it becomes very slow below pH 10 (Figure. 3).

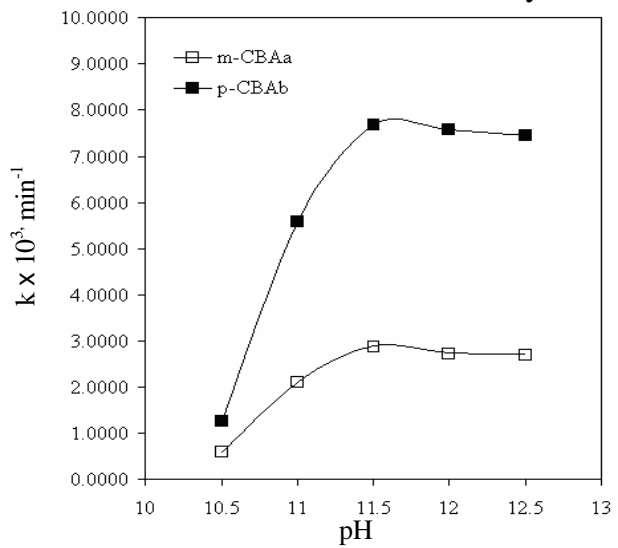

Figure 3. Effect of $\mathrm{pH} m$-CBA with time $[p$-CBA $]=4.0 \times 10-5 \mathrm{M}$, a $[2-\mathrm{Naphthol}]=2.0 \times 10^{-5} \mathrm{M}$, $\mathrm{b}[2-\mathrm{Naphthol}]=2.5 \times 10^{-5} \mathrm{M}$, light intensity $=11.8 \times 10^{-8} \mathrm{E} \mathrm{sec}-1, \mathrm{pH}=11.5$, Temperature $=298 \mathrm{~K}$ 
In the range of $\mathrm{pH} 11-12$, optimum rate constant values have been obtained and so the $\mathrm{pH}$ of the solution was maintained between 11-12 in subsequent study. The increase in $\mathrm{OH}^{-}$ ion concentration increases the sensitivity of the sensitizer, which shows higher proton transfer of 2-naphthol ${ }^{32}$.

$$
\mathrm{C}_{10} \mathrm{H}_{7} \mathrm{OH}+\mathrm{OH}^{-} \rightleftharpoons \mathrm{C}_{10} \mathrm{H}_{7} \mathrm{O}^{-}+\mathrm{H}_{2} \mathrm{O}
$$

This equilibrium between naphthol and naphthoxide ion is sensitive to $\mathrm{OH}^{-}$ion concentration of the solution. It has been reported that fluorescence of naphthoxide ion is sensitive to $\mathrm{pH}$ of the solution. The maximum fluorescence has been observed at $\mathrm{pH} 12$ and decreases as $\mathrm{pH}$ decreases ${ }^{32}$. Similar effect of $\mathrm{OH}^{-}$ion concentration has been observed in the present study.

\section{Effect of the concentration of the sensitizer}

The effect of the different concentrations of naphthoxide ion on the rate of the dechlorination has been studied by calculating the rate constants for $m$ - and $p$-CBA by using the different concentrations of 2 -naphthol in the range of $(1.0-4.0) \times 10^{-5} \mathrm{M}$. The reaction rate increases as the concentration of 2-naphthol increases, but after a limiting value of $2.0 \times 10^{-5} \mathrm{M}$ for $m$-CBA and $2.5 \times 10^{-5} \mathrm{M}$ for $p$-CBA respectively, it decreases (Figure 4). The $\lambda_{\max }$ of all compounds studied lie below $300 \mathrm{~nm}$; which do not absorb visible light. 2-Naphthoxide ions absorb light at $330 \mathrm{~nm}$ and get excited; which on collision with the substrate molecules, transfer energy to them, which undergo dechlorination and decarboxylation. The increase in the rate of photodechlorination by increasing the concentration of the sensitizer is due to the enhanced collision of excited sensitizer molecules with substrate molecules up to a limiting value. The higher sensitizer concentration increases the deactivation of the excited sensitizer molecule by intermolecular collision.

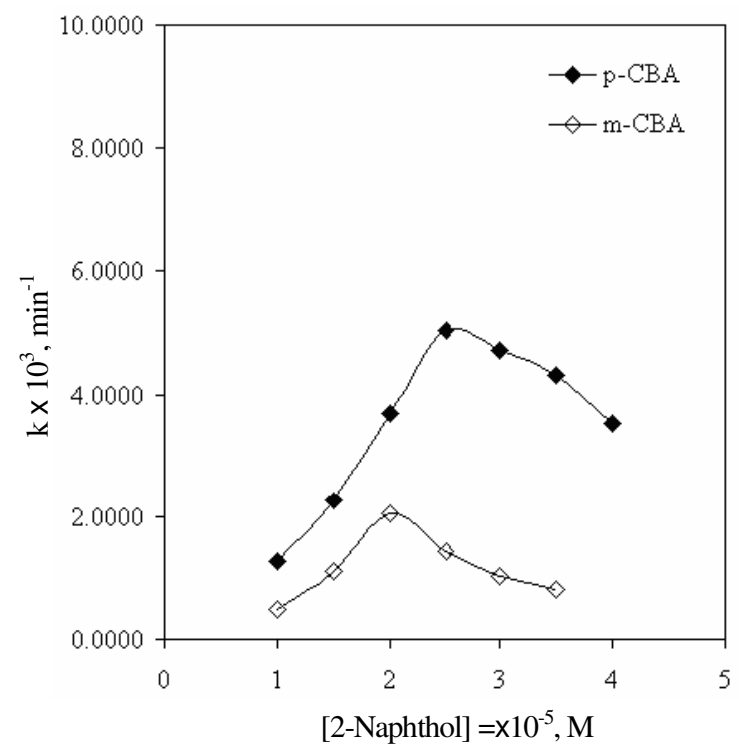

Figure 4. Effect of concentration of sensitizer $[m-\mathrm{CBA}]=[p-\mathrm{CBA}]=4 \times 10^{-5} \mathrm{M}$, light intensity $=11.8 \times 10^{-8} \mathrm{E} \mathrm{sec}-1, \mathrm{pH}=11.5$, Temperature $=298 \mathrm{~K}$. 


\section{Effect of the concentration of the substrate}

The effect of the different initial concentrations of $m$ - and $p$-CBA on the rate of the reaction has been studied. The rate of the reaction was calculated with the different initial concentrations of the substrates in the range of $(4.0-8.0) \times 10^{-5} \mathrm{M}$. The rate of the reaction remains constant with increase in the concentration of the substrate showing that the rate of the reaction is independent of the initial concentration of the substrate.

\section{Effect of the light intensity}

The increase of light intensity [Einstein / second $\left(\mathrm{E} \mathrm{sec}^{-1}\right)$ ] shows positive effect and the rate of the dechlorination increases as the light intensity increases. The number of the excited molecules of the sensitizer increases with higher light intensity as the number of photons increases and corresponding rate of the reaction increases (Table 1). A linear relationship has been observed between the light intensity and the rate of the reaction.

\section{Effect of the temperature}

The effect of the variation of the temperature has been studied between $298-328 \mathrm{~K}$ on the rate of the reaction with $10^{\circ} \mathrm{K}$ temperature interval. The rate of the reaction remains constant with the increase in the temperature in the above range. This indicates that the rate of the reaction is independent of the temperature and thermal condition does not affect the photodechlorination. The temperature independent nature of the rate of the reaction also indicates that the product formation takes place directly from the excited species without any intermediate stage.

\section{$\phi$ - Value}

The quantum efficiency has been calculated by using standard potassium ferrioxalate actinometer. $\phi$ values have also been calculated for the chlorobenzoic acids at different initial concentrations of the substrate. (Table 2). The plot of the quantum efficiency versus the concentration of the substrate (CBA) has been found to be linear with zero slope suggesting that the $\phi$ values are independent of the initial concentration of the substrate. The plot of the inverse of the quantum efficiency versus the inverse of the concentration of the substrate (CBA) has been found to be linear with zero slope ${ }^{33}$.

\section{Mechanism}

Isomeric chlorobenzoic acids absorb below $300 \mathrm{~nm}$ but naphthoxide ions absorb at $330 \mathrm{~nm}$; which is close to visible region and are fluorescent. The excited naphthoxide ions; which are in singlet state, undergo Inter System Crossing (ISC) to triplet state and emit fluorescence ${ }^{32}$ in alkaline medium. In the presence of an acceptor (CBA), the naphthoxide ions; which are in triplet state, transfers the energy to acceptor molecules (Scheme 1). The dechlorination of CBA occurs by homolytic fission at $\mathrm{C}-\mathrm{Cl}$ bond. Here simultaneous decarboxylation also takes place by forming the benzene radical, which accepts a proton from the solution and forms benzene (Scheme 2). In the case of $o$-CBA, it does not undergo dissociation under experimental condition suggesting a stable excited state. The plot of the inverse of the quantum efficiency versus the inverse of the concentration of substrate (CBA) is linear with zero slope; which indicates the decomposition of singlet excited state of acceptor molecule to the product ${ }^{33}$.

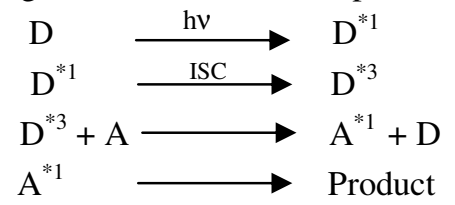

Scheme 1 
<smiles>Oc1ccc2ccccc2c1</smiles>

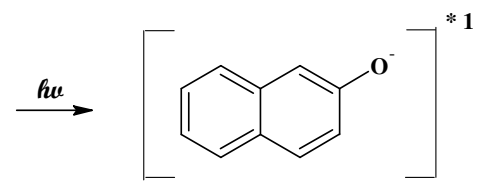<smiles>[O-]c1ccc2ccccc2c1</smiles>

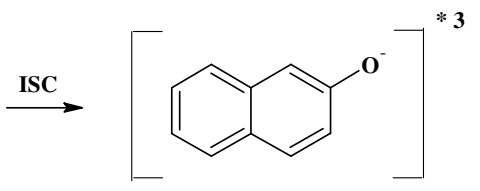

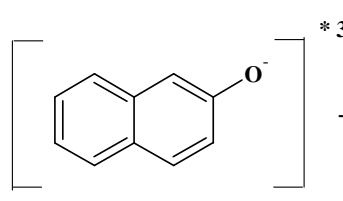<smiles>CCc1ccc(C(=O)[O-])cc1CCc1ccc2ccccc2c1</smiles><smiles>[O-]Cc1cccc(Cl)c1</smiles><smiles>O=C([O-])[O-]</smiles><smiles>c1ccccc1</smiles><smiles>[18FH]</smiles>

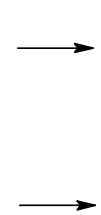<smiles>c1ccccc1</smiles>

$\mathrm{Cl}^{\circ}$

\section{Scheme 2}

\section{Conclusion}

Isomeric mono- and dichlorobenzoic acids undergo photosensitized dechlorination in the presence of naphthoxide ions in alkaline medium in the visible light. The spectral profile of the exposed solution suggests that the product of the reaction is benzene in the case of $m$ - and $p$-CBA but $o$-CBA in the case of 2,3-DCBA. However $o$-CBA does not undergo photosensitized dechlorination under experimental condition suggesting a stable excited state. The rate of the dechlorination is independent of the temperature and initial concentration of the substrate but increases with increase in the sensitizer concentration, $\mathrm{OH}^{-}$ion concentration and light intensity. The rate of the reaction shows the order $\mathrm{p}->m->0-$ chlorobenzoic acids and $\phi$ value also shows similar effect.

This method is simple, economic and effective for the dechlorination and decarboxylation of isomeric mono- and dichlorobenzoic acids using visible light source and 2-naphthol as a photosensitizer. The biggest advantage of this method is one can use direct sun light as a visible light source for bulk quantity and the cost of electricity for visible light source can be saved. 


\section{References}

1. The Merck Index, $13^{\text {th }}$ Eds., Merck \& Co. Inc.: NJ, USA, 2001, 366.

2. Renata K G and Wanda B, Polish J Chem., 1985, 59, 345.

3. Hiromichi Y, Shiho H, Yukio F and Masateru M, Bull Chem Soc Jpn., 1990, 63, 3542.

4. Jerzy K, Irena M, Lucjan S, Eugeniusz G and Mustafa H M M, Collect Czech Chem Commun., 1990, 55, 80.

5. Richnow H H, Seifert R, Hefter J, Kastner M, Mahro B and Michaelis W, Org Geochem., 1994, 22, 671.

6. Fava F, Di Gioia D, Bignami A and Marchetti L, Chemosphere, 1994, 29, 39.

7. Espandiari P, Thomas V A, Glauert H P, O'Brien M, Noonan D and Robertson L W, Fundam Appl Toxicol., 1995, 26, 85.

8. Cassel J C and Jeltsch H, Neuroscience, 1995, 69, 1-41.

9. Jinno H, Hanioka N, Takahashi A, Nishimura T, Toyo' Oka T and Ando M, Toxicol Vitro, 1997, 11, 731-739.

10. Di Gioia D, Fava F, Baldoni F and Marchetti L, Res Microbiol., 1998, 149, 339-348.

11. Kobayashi K, Katayama-Hirayama K and Tobita S, J Gen Appl Microbiol., 1997, 43, 105-108.

12. Gerritse J, Van der Woude B J and Gottschal J C, FEMS Microbiol Lett., 1992, 100, 273-280.

13. Kozlovsky S A, Zeitsev G M, Kunc F, Gabriel J and Boronin A M, Folia Microbiol., 1993, 38(5), 371-375.

14. Kozlovsky S A, Zeitsev G M and Kunc F, Folia Microbiol., 1993, 38(75), 376-378.

15. Siciliano S D and Germida J J, Environ Toxicol Chem., 1998, 17, 728-733.

16. Baggi $\mathrm{G}$ and Zangrossi M, FEMS Microbiol Ecol., 1999, 29, 311-318.

17. Hidaka H, Honjou H, Takayoshi K, Mitsutsuka Y, Oyama T and Serpone N, $J$ Photochem Photobiol A Chem., 2008, 197, 115-123.

18. Dionysiou D D, Makram T S, Evanqelia B, Isabelle B and Jean-Michel L, Appl Catal B Environmental, 2000, 26, 153 .

19. D'Oliveira J C, Jayatilake W D W, Tennakone K, Herrmann J M and Pichat P, Stud Surf Sci Catal., 1993, 75, 2167.

20. Tahiri H, Ichaon Y A and Herrmann J M, J Photochem Photobiol A Chem., 1998, 114, 219.

21. Jean-Marie H, Chantal G, Jean D, Corinne L, Sixto M and Julian B, Appl Catal B Environmental, 2002, 35, 281-294.

22. Ormad P, Cortes S, Puig A, and Ovelleiro J L, Wat Res., 1997, 31, 2387-2391.

23. Cho M, Chung H, Choi W and Yoon J, Water Res., 2004, 38, 1069.

24. Liang J, Komarov S, Hayashi N and Kasai E, J Mater Cycles Waste Manag., 2007, 9, 47-55.

25. Dwivedi A H and Pande U C, J Photochem Photobiol A Chem., 2003, 154, 303-309.

26. Dwivedi A H and Pande U C, J Indian Chem Soc., 2005, 82, 424-427.

27. Baumgartner M T, Pierini A B and Rossi R A, J Org Chem., 1993, 58, 2593.

28. Soumillion J Ph, Vandereecken P and Schryver F C De, Tetrahedron Lett., 1989, 30, 697.

29. Kazuhiro M, Seiji T and Hiroshi I, Bull Chem Soc Jpn., 1986, 59, 1777.

30. Maria T B, Adriana B P and Roberto A R, J Org Chem., 1993, 58, 2593.

31. Kiyomi K, Bunji Y, Masahiko K, Masaki U, Yoshito T and Yoshinobu O, J Org Chem., 1993, 58, 2797.

32. Rohatgi-Mukherjee K K, Fundamentals of photochemistry $3^{\text {rd }}$ Eds., New Age International (P) Ltd New Delhi, India, 1997, 107.

33. Freeman P K, Jung-Suk J and Ramnath N, J Org Chem., 1991, 56, 6072. 


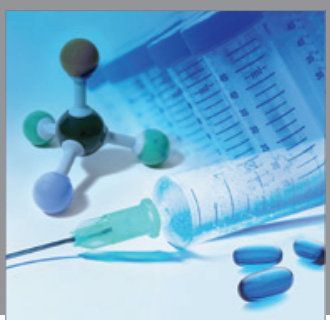

International Journal of

Medicinal Chemistry

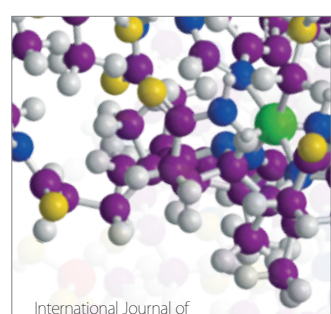

Carbohydrate Chemistry

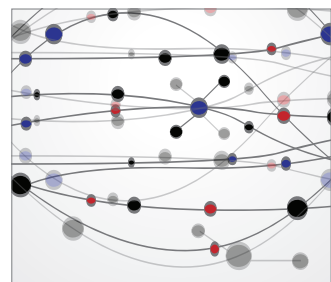

The Scientific World Journal
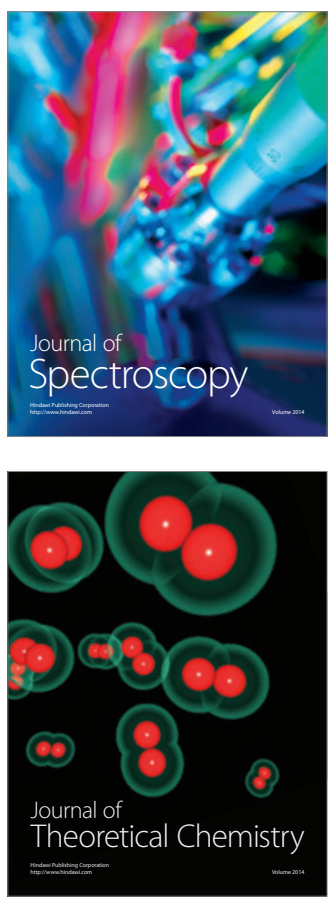
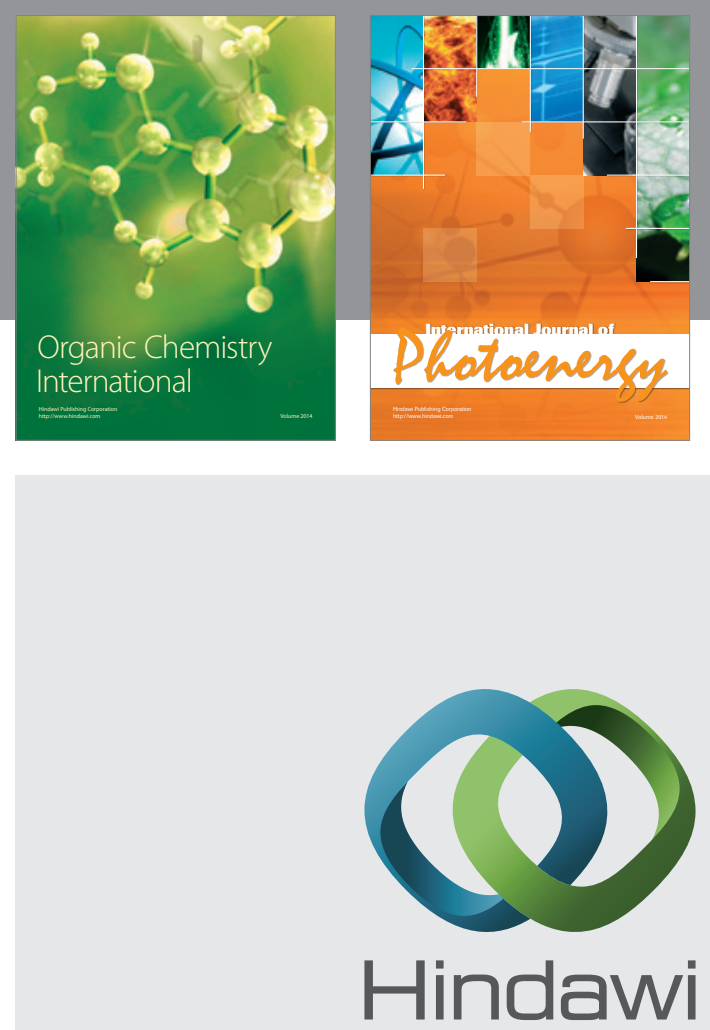

Submit your manuscripts at

http://www.hindawi.com
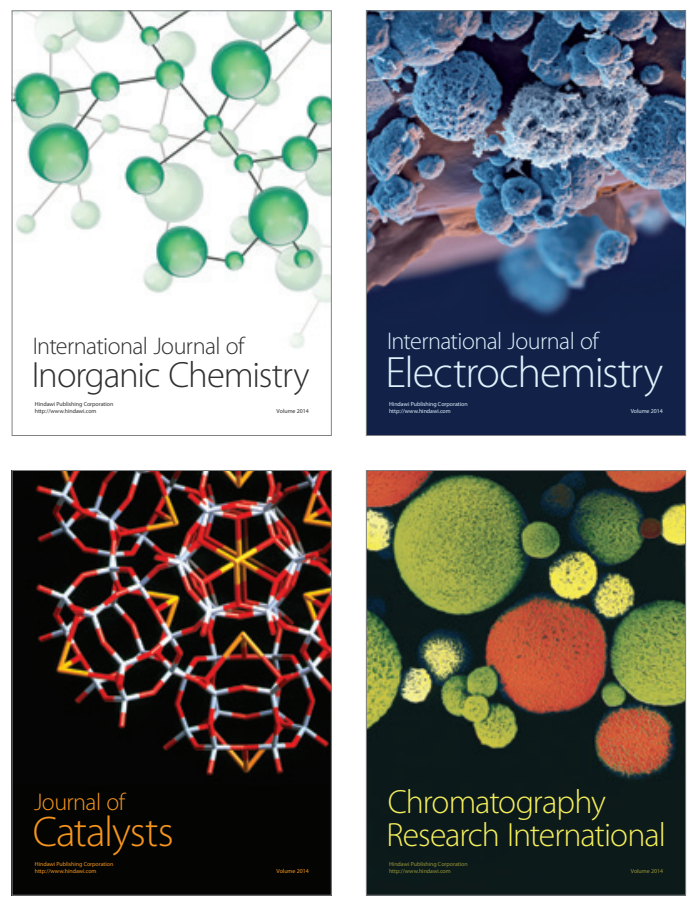
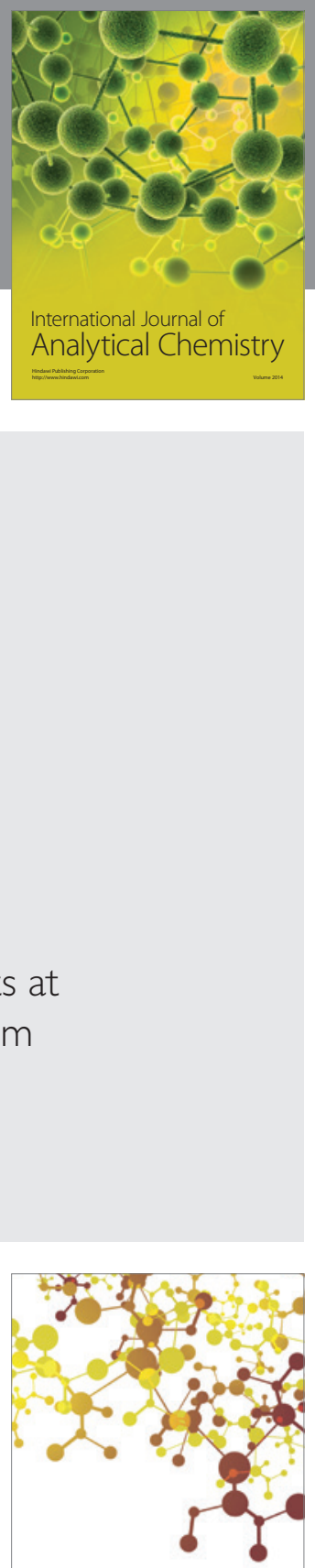

Journal of

Applied Chemistry
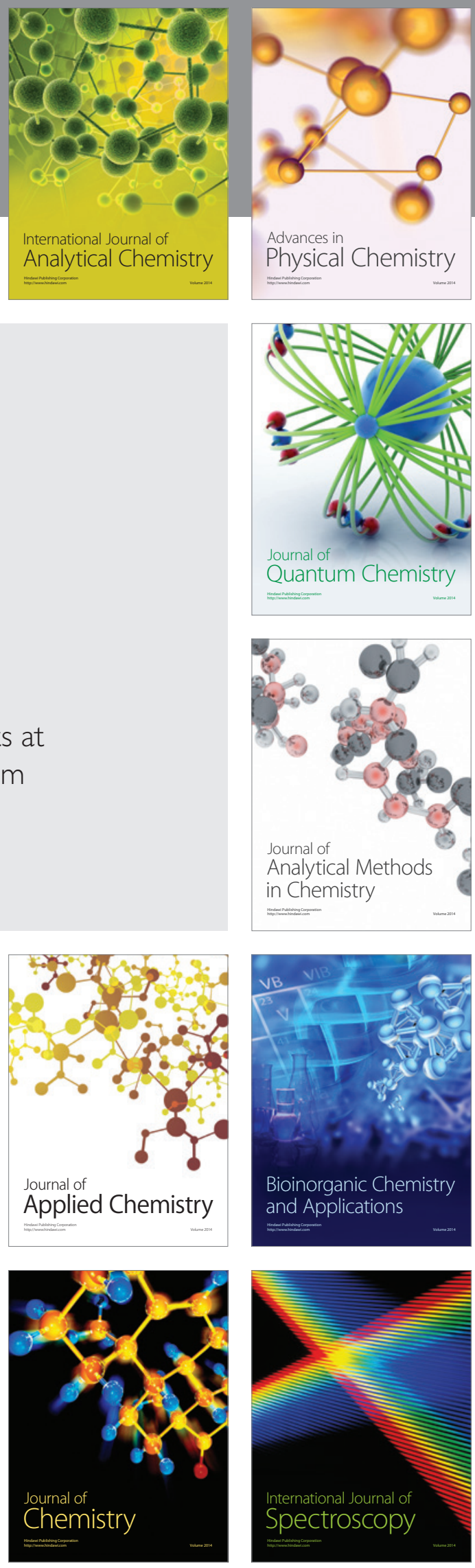